\title{
Pengembangan Storyboard Game Sekolah
}

\author{
Rifqi Ramadhani'1a, Zaki Mukhammadb, Tegar Aditia Pratama1c, M. Ainul Yaqin ${ }^{1 d}$ \\ ${ }^{1}$ Teknik Informatika, UIN Maulana Malik Ibrahim Malang \\ Jalan Gajayana No. 50 \\ Email : ${ }^{a}$ rifqird98@gmail.com, ${ }^{b}$ zakimuhammad20@gmail.com, ${ }^{c}$ tegara946@gmail.com, \\ dyaqinov@ti.uin-malang.ac.id
}

\begin{abstract}
The school is a very important place of learning for every Indonesian citizen. Receiving education is the right of Indonesian citizens who have been guaranteed by the 1945 Constitution. Therefore, every Indonesian citizen has the right to get an easily accessible and quality education. To go to quality schools, each school must meet National Education Standards. Meeting the quality standards of schools needs to implement rules that are expected to increase the quality of each school. The rule then needs to be tested which sometimes the process is very long and prone to failure in the middle of the rule is applied. In this study, researchers created a school game storyboard that is expected to help the process of testing a rule so that it does not need to take a very long time. From the results of the storyboards that have been made it can be seen that building a quality school must be started and arranged from level 1.
\end{abstract}

Keywords: storyboard, game, school

Sekolah merupakan tempat belajar yang sangat penting bagi setiap bagi setiap warga negara Indonesia. Menerima pendidikan merupakan hak warga negara Indonesia yang telah dijamin oleh Undang-Undang Dasar 1945. Oleh karena itu, setiap warga negara Indonesia berhak mendapatkan pendidikan yang mudah diakses dan berkualitas. Untuk menuju ke sekolah yang berkualitas maka setiap sekolah harus memenuhi Standar Nasional Pendidikan. Pemenuhan standar sekolah yang berkualitas perlu menerapkan aturan yang diharapkan dapat menambah kualitas setiap sekolah. Aturan tersebut kemudian perlu dilakukan uji coba yang terkadang prosesnya sangat panjang dan rawan gagal di tengah aturan tersebut diterapkan. Pada penelitian ini, peneliti membuat storyboard game sekolah yang diharapkan dapat membantu proses uji coba sebuah aturan sehingga tidak perlu memakan waktu yang sangat lama. Dari hasil storyboard yang telah dibuat dapat dilihat bahwasanya untuk membangun sekolah yang bermutu harus dimulai dan disusun dari level 1.

Kata kunci: storyboard, game, sekolah

\section{PENDAHULUAN}

Tujuan pendidikan nasional yaitu mengembangkan potensi peserta didik agar menjadi manusia yang beriman dan bertakwa kepada Tuhan Yang Maha Esa, berakhlak mulia, sehat, berilmu, cakap, kreatif, mandiri, dan menjadi warga negara yang demokratis serta bertanggung jawab [1]. Dalam Peraturan Pemerintah Nomor 19 Tahun 2005 tentang Standar Nasional Pendidikan dinyatakan bahwa Standar Nasional Pendidikan (SNP) adalah kriteria minimal tentang sistem pendidikan di seluruh wilayah hukum Negara Kesatuan Republik Indonesia [2]. Standar Nasional Pendidikan (SNP) terdiri dari standar isi, proses, pendidik dan tenaga kependidikan, kompetensi lulusan, sarana dan prasarana, pembiayaan, pengelolaan, dan penilaian. Dengan adanya standar nasional tersebut, maka arah peningkatan mutu pendidikan Indonesia menjadi lebih jelas [3]. Hal ini ditegaskan 
juga oleh Hidayah, Susilowati, dan Sukirman, yang menyatakan bahwa pemenuhan SNP dilakukan guna mewujudkan pelaksanaan pendidikan yang bermutu [4].

Sekolah merupakan lembaga yang diberi kewenangan untuk menghasilkan generasi-generasi penerus bangsa. Sekolah yang bermutu akan menghasilkan output yang bermutu pula. Mutu merupakan suatu konsep atau pandangan mengenai mutu produk yang sesuai harapan dengan tingkat kepuasan tertentu yang dirasakan oleh pelanggan dan seluruh stakeholder [4]. Untuk meningkatkan mutu sekolah selama ini masih belum ada strategi yang menjelaskan atau menggambarkan bagaimana merancang sebuah strategi untuk membangun sebuah sekolah yang bermutu, dimulai dari tahap perintisan hingga bisa dikatakan dalam sekolah bermutu. Oleh karena itu perlu adanya rancangan atau aturan-aturan yang dapat memberikan simulasi bagaimana menyusun strategi untuk pengembangan sekolah, mulai dari tahap awal sampai terbentuknya sebuah sekolah yang bermutu. Dalam penelitian ini rancangan dan aturan-aturan tersebut dikemas dalam bentuk sebuah storyboard game sekolah, yang didalamnya terdapat sebuah strategi bagaimana cara membangun sebuah sekolah

\section{METODOLOGI PENELITIAN}

\subsection{Analisis Kebutuhan}

Dalam membangun storyboard game sekolah ada beberapa hal yang dibutuhkan yaitu:

\section{a. Uang}

Uang adalah faktor penting disetiap game, karena dibutuhkan untuk membeli item atau mengupgrade item. Uang dalam story board game sekolah ini menggunakan mata uang rupiah (Rp). Pada story boad game sekolah ini player akan mendapatkan uang sebesar Rp1000 setiap 10 detik di waktu normal. Selain itu player juga bisa mendapatkan uang dengan cara menyelesaikan misi yang dijelaskan di tabel 5 dan juga dengan menaikkan level seperti yang tertera pada tabel 4.

\section{b. Sarana dan Prasarana}

Pada rancangan game ini terdapat sarana dan prasarana yang dapat dibeli oleh player. Sarana dan Prasarana ini terdiri atas bangunan dan barang. Metode pembelian sarana dan prasarana ini menggunakan uang yang menggunakan mata uang rupiah. Berikut adalah tabel dari daftar sarana prasarana.

Tabel 1. Sarana dan Prasarana

\begin{tabular}{|l|l|l|l|l|l|}
\hline \multicolumn{7}{|c|}{ SARANA DAN PRASARANA } \\
\hline \multicolumn{1}{|c|}{ Katagori } & Level & \multicolumn{1}{c|}{ Harga } & Perawatan & Waktu (Menit) & Xp \\
\hline Kelas & 1 & Rp25.000.000,00 & Rp5.000.000,00 & 2,5 & 2 \\
\hline Ruang Guru & 1 & Rp25.000.000,00 & Rp5.000.000,00 & 2,5 & 2 \\
\hline Ruang Kapsek & 1 & $\mathrm{Rp} 25.000 .000,00$ & $\mathrm{Rp} 5.000 .000,00$ & 2,5 & 2 \\
\hline Tempat Parkir & 1 & $\mathrm{Rp} 10.000 .000,00$ & $\mathrm{Rp} 2.000 .000,00$ & 1 & 2 \\
\hline Kamar mandi & 1 & $\mathrm{Rp} 5.000 .000,00$ & $\mathrm{Rp} 1.000 .000,00$ & 0,5 & 2 \\
\hline Perpustakaan & 1 & $\mathrm{Rp} 15.000 .000,00$ & $\mathrm{Rp} 3.000 .000,00$ & 1,5 & 2 \\
\hline Alat-alat kebersihan & 1 & $\mathrm{Rp} 5.000 .000,00$ & $\mathrm{Rp} 1.000 .000,00$ & - & 2 \\
\hline
\end{tabular}


Jurnal Riset Sistem Informasi Dan Teknik Informatika (JURASIK)

Volume 5 Nomor 1 Februari, pp 1-6

ISSN: 2527-5771/EISSN: 2549-7839

http://tunasbangsa.ac.id/ejurnal/index.php/jurasik

\begin{tabular}{|c|c|c|c|c|c|}
\hline \multicolumn{6}{|c|}{ SARANA DAN PRASARANA } \\
\hline Katagori & Level & Harga & Perawatan & Waktu (Menit) & $\mathbf{X p}$ \\
\hline Meja & 1 & Rp200.000,00 & Rp40.000,00 & - & 2 \\
\hline Buku & 1 & Rp12.000,00 & Rp2.400,00 & - & 2 \\
\hline Kursi & 1 & Rp200.000,00 & Rp40.000,00 & - & 2 \\
\hline Meja Guru & 1 & Rp200.000,00 & Rp40.000,00 & - & 2 \\
\hline Papan Tulis & 1 & Rp200.000,00 & Rp40.000,00 & - & 2 \\
\hline Ruang TU & 2 & Rp25.000.000,00 & Rp5.000.000,00 & 2,5 & 4 \\
\hline Ruang Ekskul & 2 & Rp25.000.000,00 & Rp5.000.000,00 & 2,5 & 4 \\
\hline Ruang Kesiswaan & 3 & Rp25.000.000,00 & Rp5.000.000,00 & 2,5 & 6 \\
\hline Ruang OB & 3 & Rp10.000.000,00 & Rp2.000.000,00 & 1 & 6 \\
\hline UKS & 3 & Rp10.000.000,00 & Rp2.000.000,00 & 1 & 6 \\
\hline Tempat Beribadah & 3 & Rp50.000.000,00 & Rp10.000.000,00 & 5 & 6 \\
\hline Pos Satpam & 4 & Rp10.000.000,00 & Rp2.000.000,00 & 1 & 8 \\
\hline Mobil & 4 & Rp100.000.000,00 & Rp20.000.000,00 & - & 8 \\
\hline Tempat Olahraga & 4 & Rp500.000.000,00 & Rp100.000.000,00 & 50 & 8 \\
\hline Kantin & 5 & Rp50.000.000,00 & Rp10.000.000,00 & 5 & 10 \\
\hline Bus & 5 & Rp250.000.000,00 & Rp50.000.000,00 & - & 10 \\
\hline Ruang Lab & 5 & Rp30.000.000,00 & Rp6.000.000,00 & 3 & 10 \\
\hline
\end{tabular}

Level di tabel artinya sarana dan prasarana tersebut hanya terdapat pada level yang tertera. Kemudian harga adalah biaya pembelian item sarana prasarana tersebut. Biaya perawatan adalah biaya yang dibebankan kepada player untuk menjaga kualitas sarana dan prasarana. Waktu merupakan lama waktu yang dibutuhkan untuk membuat sarana prasarana tersebut di game. Terakhir, XP adalah bonus XP yang diberikan ketika player membeli item tersebut.

\section{c. Karakter}

Pada rancangan story board game sekolah ini juga terdapat karakter. Karakter adalah NPC (Non-Player Character) yang terdapat di game. Karakter ini terdiri dari guru dan pegawai. Karakter dapat dibeli oleh player dengan menggunakan uang. Berikut adalah tabel karakter.

Tabel 2. Karakter

\begin{tabular}{|l|l|l|l|l|}
\hline \multicolumn{5}{|c|}{ KARAKTER } \\
\hline \multicolumn{1}{|c|}{ Nama } & Level & Biaya Rekrut & \multicolumn{1}{c|}{ Gaji } & XP \\
\hline Guru & 1 & Rp200.000,00 & Rp2.000.000,00 & 3 \\
\hline Kepala Sekolah & 1 & Rp250.000,00 & Rp2.500.000,00 & 3 \\
\hline Tukang Kebun & 2 & Rp60.000,00 & Rp600.000,00 & 5 \\
\hline Office Boy & 3 & Rp60.000,00 & Rp600.000,00 & 8 \\
\hline Paramedis & 3 & Rp80.000,00 & Rp800.000,00 & 8 \\
\hline Satpam & 4 & Rp70.000,00 & Rp700.000,00 & 10 \\
\hline Driver & 4 & $R p 50.000,00$ & Rp500.000,00 & 10 \\
\hline Laboran & 4 & $R p 100.000,00$ & Rp1.000.000,00 & 10 \\
\hline Koki & 5 & Rp100.000,00 & Rp1.000.000,00 & 13 \\
\hline Pelatih & 5 & Rp150.000,00 & Rp1.500.000,00 & 13 \\
\hline
\end{tabular}


Level pada tabel 2 menunjukkan bahwa karakter tersebut hanya dapat dibeli pada level yang tertera. Kemudian biaya rekrut merupakan biaya yang dibebankan kepada player jika ingin merekrut karakter. Lalu gaji adalah biaya yang dikeluarkan player per bulan untuk membayar karakter. Dan terakhir, XP adalah bonus XP yang diberikan kepada player jika membeli karakter tersebut.

\section{HASIL DAN PEMBAHASAN}

Pada pengembangan story board ini terdapat aturan-aturan sebagai acuan player untuk memulai permainan, aturan ini difungsikan untuk memberi gambaran secara deskriptif tentang aturan yang ada dalam game sekolah.

Tabel 3. Aturan

\begin{tabular}{|c|l|}
\hline No & \multicolumn{1}{|c|}{ Aturan } \\
\hline 1. & player harus menyelesaikan misi pada setiap level \\
\hline 2. & Player mendapatkan uang pertama senilai 75000000 \\
\hline 3. & Untuk mendaptkan siswa player harus mengumpulkan 50xp untuk 10 siswa \\
\hline 4. & Player akan mendapatkan bunus setiap ada siswa yang diperoleh \\
\hline 5. & player harus memenuhi fasilitas siswa, jika ada sebagian siswa tidak mendapatkan fasilitas maka siswa akan pergi \\
\hline 6. & setiap misi yang telah diselesaikan player akan mendapatkan bonus \\
\hline 7. & setiap naik level player akan mendapatkan bonus \\
\hline 8. & player dapat mendapatkan bonus tambahan dengan membangun usaha dalam sekolah \\
\hline 9. & player mendapatkan uang sewa dari cafetaria \\
\hline 10. & semakin tinggi level semakin banyak kebutuhan siswa dan sekolah yang harus dipenuhi \\
\hline
\end{tabular}

Aturan-aturan diatas dijadikan sebuah pedoman untuk player memutuskan tindakan dalam membangun sebuah sekolah melalui misi-misi yang telah dibuat. Pada story board game sekolah ini dibuat setiap player memenuhi batas XP yang tertera di tabel 4, maka player berhak untuk mendapatkan bonus uang dan XP sesuai level, seperti yang tertera pada tabel 4 dibawah ini:

Tabel 4. Level XP

\begin{tabular}{|c|c|c|c|c|c|}
\hline Level & Sarana dan Prasarana & Karakter & Bonus Money & Batas XP & To Next Level (XP) \\
\hline \multirow[t]{12}{*}{1} & 3 Kelas & 4 Guru & \multirow[t]{12}{*}{ Rp10.000.000,00 } & \multirow[t]{12}{*}{75} & \multirow[t]{12}{*}{27} \\
\hline & Ruang Guru & Kepala Sekolah & & & \\
\hline & Ruang Kepala Sekolah & & & & \\
\hline & Tempat Parkir & & & & \\
\hline & 2 Kamar Mandi & & & & \\
\hline & Perpustakaan & & & & \\
\hline & Alat-alat kebersihan & & & & \\
\hline & Meja & & & & \\
\hline & 20 Buku & & & & \\
\hline & Kursi & & & & \\
\hline & Meja Guru & & & & \\
\hline & 3 Papan tulis & & & & \\
\hline 2 & Ruang Tata Usaha & 6 Guru & Rp20.000.000,00 & 278 & 7 \\
\hline
\end{tabular}


Jurnal Riset Sistem Informasi Dan Teknik Informatika (JURASIK)

Volume 5 Nomor 1 Februari, pp 1-6

ISSN: 2527-5771/EISSN: 2549-7839

http://tunasbangsa.ac.id/ejurnal/index.php/jurasik

\begin{tabular}{|c|c|c|c|c|c|}
\hline Level & Sarana dan Prasarana & Karakter & Bonus Money & Batas XP & To Next Level (XP) \\
\hline & Ruang Kesiswaan & Tukang Kebun & & & \\
\hline & 6 Kelas & Tata Usaha & & & \\
\hline & 60 Buku & & & & \\
\hline & 4 Kamar Mandi & & & & \\
\hline \multirow[t]{7}{*}{3} & 9 Kelas & 8 Guru & \multirow[t]{7}{*}{ Rp40.000.000,00 } & \multirow[t]{7}{*}{577} & \multirow[t]{7}{*}{14} \\
\hline & Ruang Eskul & Office Boy & & & \\
\hline & Ruang OB & Paramedis & & & \\
\hline & Ruang UKS & & & & \\
\hline & Tempat Ibadah & & & & \\
\hline & 100 Buku & & & & \\
\hline & 6 Kamar Mandi & & & & \\
\hline \multirow[t]{6}{*}{4} & Pos Satpam & Satpam & \multirow[t]{6}{*}{ Rp80.000.000,00 } & \multirow[t]{6}{*}{1017} & \multirow[t]{6}{*}{30} \\
\hline & Mobil & Driver & & & \\
\hline & Ruang Lab & Laboran & & & \\
\hline & 12 Kelas & 10 Guru & & & \\
\hline & 150 Buku & & & & \\
\hline & 8 Kamar Mandi & & & & \\
\hline \multirow[t]{6}{*}{5} & Bus & Koki & \multirow[t]{6}{*}{ Rp160.000.000,00 } & \multirow[t]{6}{*}{1587} & \multirow[t]{6}{*}{50} \\
\hline & Kantin & Pelatih & & & \\
\hline & Tempat Olahraga & 12 Guru & & & \\
\hline & 15 Kelas & & & & \\
\hline & 200 Buku & & & & \\
\hline & 10 Kamar Mandi & & & & \\
\hline
\end{tabular}

Dalam misi-misi yang telah dibuat menggambarkan bagaimana membangun sebuah sekolah dari level 1 dimana memulai membagun sebuah sekolah yang dengan sarana dan prasarana yang minim, siswa dan pegajar yang sedikit hingga mencapai level 5 yang dapat dikatakan sebagai sekolah bermutu. Untuk mencapai level 5 player harus memenuhi misi-misi setiap level, adapun misi yang pertama kali harus diselesaikan adalah seperti tabel 5 berikut :

Tabel 5. Misi

\begin{tabular}{|l|l|l|l|}
\hline \multicolumn{4}{|c|}{ MISSION } \\
\hline Level & \multicolumn{1}{|c|}{ Misi } & \multicolumn{1}{|c|}{ Bonus Money } & Bonus XP \\
\hline 1 & Beli 3 Kelas & Rp7.500.000,00 & 5 \\
\hline & Beli 2 Kamar Mandi & Rp1.000.000,00 & 5 \\
\hline & Beli 20 Buku & Rp24.000,00 & 5 \\
\hline 2 & Beli 6 Kelas & Rp15.000.000,00 & 10 \\
\hline & Beli 4 Kamar Mandi & Rp2.000.000,00 & 10 \\
\hline & Beli 60 Buku & Rp72.000,00 & 10 \\
\hline 3 & Beli 9 Kelas & Rp22.500.000,00 & 15 \\
\hline & Beli 6 Kamar Mandi & Rp3.000.000,00 & 15 \\
\hline & Beli 100 Buku & Rp120.000,00 & 15 \\
\hline 4 & Beli 12 Kelas & Rp30.000.000,00 & 20 \\
\hline
\end{tabular}


http://tunasbangsa.ac.id/ejurnal/index.php/jurasik

\begin{tabular}{|l|l|l|l|}
\hline \multicolumn{4}{|c|}{ MISSION } \\
\hline Level & \multicolumn{1}{|c|}{ Misi } & \multicolumn{1}{|c|}{ Bonus Money } & Bonus XP \\
\hline & Beli 8 Kamar Mandi & Rp4.000.000,00 & 20 \\
\hline & Beli 150 Buku & Rp180.000,00 & 20 \\
\hline 5 & Beli 15 Kelas & Rp37.500.000,00 & 25 \\
\hline & Beli 10 Kamar Mandi & Rp5.000.000,00 & 25 \\
\hline & Beli 200 Buku & Rp240.000,00 & 25 \\
\hline
\end{tabular}

Misi diatas harus terpenuhi jika player mengingingkan tambahan money. Setiap misi pada tabel 5 akan terbuka ketika player sudah berada pada level yang sesuai. Player level 1 tidak akan bisa mengakses misi level 2, dan seterusnya. Setiap misi yang diselesaikan player akan mendapatkan reward berupa money dan XP.

\section{SIMPULAN}

Dari rancangan storyboard game sekolah yang telah dibuat, dapat diambil kesimpulan sebagai berikut:

a. Story board game sekolah ini dapat dikembangkan untuk menjadi sebuah game dengan menerapkan aturan dan hal-hal yang telah ditetapkan diatas.

b. Story board game sekolah ini dapat dikembangkan lagi dengan menambah level menjadi lebih banyak.

\section{DAFTAR PUSTAKA}

[1] Undang-Undang Nomor 20 Tahun 2003

[2] Peraturan Pemerintah Republik Infonesia Nomor 19 Tahun 2005 Tentang Standar Nasional Pendidikan.

[3] Raharjo, S. B. 2012. Evaluasi trend kualitas pendidikan di indonesia. Jurnal Penelitian Dan Evaluasi Pendidikan, 16(2): 511-532.

[4] Ririn Tius E. M \& Bambang Ismanto. 2017. Strategi Perencanaan Pembiayaan Sekolah dalam Peningkatan Mutu di SMP Negeri. kelola rumah jurnal pendidikan, 4(2):195-2014 